\title{
Capacitação teórica do enfermeiro para o atendimento da parada cardiorrespiratória
}

\author{
Theoretical training for nurses in cardiac arrest attendance \\ Capacitación teórica del enfermero para el atendimiento del paro cardiorespiratorio
}

\author{
Margarete Consorti Bellan', Izilda Ismenia Muglia Araújo", Sebastião Araújo"I \\ 'Universidade Estadual de Campinas. Colégio Técnico. Campinas, SP \\ "Universidade Estadual de Campinas. Faculdades de Ciências Médicas. Departamento de Enfermagem. Campinas, SP \\ "'Universidade Estadual de Campinas. Faculdade de Ciências Médicas. Departamento de Cirurgia. Campinas, SP
}

Submissão: 25/05/2010

Aprovação: $27 / 07 / 2010$

\section{RESUMO}

Objetivos do estudo: aplicar um programa de capacitação teórica para enfermeiros na ressuscitação cardiopulmonar e comparar o conhecimento teórico do grupoA-controle com o grupoB-experimental. O programa contemplou três etapas: etapa-I, avaliação précapacitação teórica; etapas-II e III, avaliação teórica recente (uma semana após etapa-I) e tardia (três meses após etapa-I). Amostra composta por enfermeiros assistenciais, 21 no grupo-A e 38 no grupo-B. Verificou-se que a média das notas no grupo-A variou de forma progressiva: 6,45; 6,66 e 7,10; e, no grupo-B, de forma oscilante: 6,48; 8,36 e 8,0; etapas II e III (p<0,00 I). Concluiu-se Que o grupo-B foi superior ao grupo-A. Entretanto, o desempenho do grupo-B etapa-II foi superior ao da etapa-III, eneuanto o grupo-A apresentou melhora progressiva.

Descritores: Parada cardíaca; Ressuscitação cardiopulmonar; Capacitação em serviço.

\section{ABSTRACT}

Objectives of the study: to apply a theoretical Qualification program for nurses in cardiopulmonary resuscitation and compare the theoretical knowledge group-A-control with group-B-experimental. This program comprised three stages: Stage-I, evaluation pre-theoretical Qualification; Stages-II and III, evaluation of the recent (one week after stage-I) and later (three months after stage-I) Qualification. The sample was composed of 21 nurses in Group-A and 38 in Group-B. The mean performance score in Group-A varied in a progressive form: 6.45; 6.66 and 7.10; in Group-B, in an oscillating form: 6.48; 8.36 and 8.0; stages II and III ( $p<0,001$ ). It was concluded that: Group-B has been superior to Group-A. However, the performance of Group-B stage-II was superior to stage-III, while in the Group-A it was observed a gradual improvement.

Key words: Cardiac arrest; Cardiopulmonary resuscitation; Qualification in service.

\section{RESUMEN}

Objetivos del estudio: aplicar un programa de capacitatión teórica para enfermeros en la resucitación cardiopulmonar y comparar el conocimiento teórico del grupo A-control con el grupo B-experimental. El programa contemplo três etapas: etapa-I, evaluación précapacitación teórica; etapas-II e III, evaluación teórica reciente (una semana después de la etapa-I) y tardia (três meses después de la etapa-I). La muestra fue compuesta por enfermeros asistenciales, $2 \mathrm{I}$ en el grupo-A y 38 en el grupo-B. Se observo Que el puntage medio del grupo-A presentó una variación progresiva: 6,$45 ; 6,66$ y 7,$10 ;$, en el grupo-B, de fuerma oscilante: 6,$48 ; 8,36$ y 8,0: etapas II y III $(\mathrm{p}<0,00 \mathrm{I})$. Se concluyó Que el grupo-B fue superior al grupo-A. Entremientes, el desempeno del grupo-B etapa-II fue superior al de la etapa-III, mientras el grupo-A presentó mejorías progressivas.

Descriptores: Paro cardíaco; Resucitación cardiopulmonar; Capacitación en servicio.

AUTOR CORRESPONDENTE Margarete Consorti Bellan. Rua Proença, 844 apto 22. CEP I 3026-121. Campinas, SP.

E-mail: margaretebellan@uol.com.br 


\section{INTRODUÇÃO}

Os profissionais da área de saúde deparam-se constantemente com situações Que reQuerem atuação imediata e rápida, pois envolvem risco para o paciente. A parada cardiorrespiratória (PCR) é um dos exemplos, uma vez Que a chance de sobrevivência após o evento varia de $2 \%$ a $49 \%$ dependendo do ritmo cardíaco inicial e do início precoce da reanimação(l).

Com o progressivo aumento na freeuência da PCR em áreas não críticas, há necessidade de capacitação de todos os profissionais de saúde, pois a sobrevivência do paciente depende da competência e instituição imediata das manobras de ressuscitação cardiopulmonar $(\mathrm{RCP})^{(2)}$.

Considerando Que na maioria das vezes o enfermeiro é o membro da equipe que primeiro se depara com a situação de $\mathrm{PCR}^{(3-5)}$, este precisa possuir conhecimentos sobre atendimento de emergência, com tomada de decisões rápidas, avaliação de prioridades e estabelecimento de ações imediatas ${ }^{(4,6)}$.

$\mathrm{Na}$ formação do enfermeiro, os conteúdos teóricos e práticos relacionados à PCR e manobras de RCP têm sido ministrados de forma superficial, limitados, e muitas vezes não supre as necessidades dos alunos ${ }^{(7)}$. As dificuldades refletirão na prática do enfermeiro, pois só a experiência profissional não oferece subsídios e embasamentos teóricos suficientes para suprir este déficit ${ }^{(8)}$.

Os programas de capacitação Que existem são destinados aos profissionais médicos, enfermeiros e paramédicos ${ }^{(9)}$, principalmente os Que trabalham e se deparam com situações de urgência e emergência. Também há os de preparação de profissionais para atuarem como instrutores ou auditores de $\operatorname{cursos}^{(10)}$.

Um estudo do final da década de 90 constatou Que houve diversificação entre os tipos de cursos, tempos destinados à teoria e à prática e à categoria profissional mais participativa. Os enfermeiros foram os profissionais Que mais receberam treinamento em suporte básico (SBV) ou suporte avançado de vida (SAV), ou em ambos ${ }^{(3)}$.

O treinamento das manobras de RCP deve estar voltado para a aQuisição de conhecimento teórico, habilidades práticas e atitudes dos profissionais, trabalhados concomitantemente, e dentro do contexto da prática dos participantes, para facilitar sua atuação $0^{(3 .}$ 5). A padronização das condutas na RCP ajuda na adoção de linguagem única dos profissionais de saúde para executar as manobras com eficácia ${ }^{(1)}$.

Os cursos de SBV e SAV são oferecidos regularmente no Brasil, hoje, sob a permissão e supervisão da American Heart Association, propiciando o conhecimento com tecnologia adeQuada e certificação da atuação dos profissionais, porém, muitas vezes, estão fora das possibilidades financeiras dos interessados.

Propor, então, um programa de capacitação do enfermeiro para o atendimento da PCR/RCP é aproximar da sua realidade prática os conhecimentos Que estão sendo produzidos a respeito do assunto, e também contribuir para Que haja uma padronização e uniformização do atendimento da PCR/RCP na instituição pesquisada.

Em um estudo ${ }^{(12)}$ os profissionais demonstraram a preocupação em corresponder com os avanços tecnológicos nos serviços de saúde e com isso a necessidade de educação no trabalho ligada às demandas de atualização profissional.
Diante do exposto, o objetivo principal deste estudo foi elaborar e aplicar um programa de capacitação teórica para o enfermeiro na PCR/RCP e comparar o conhecimento do grupo-A-controle com o grupo-B-experimental.

\section{MÉTODOS}

Tratou-se de uma investigação prospectiva, intervencionista e comparativa realizada em um hospital escola do interior do Estado de São Paulo, com 402 leitos, de atendimento terciário e Quaternário.

A população foi constituida pelos enfermeiros dos períodos manhã, tarde e noite, das diversas unidades de internação do hospital, totalizando 285 profissionais. Foram incluídos na amostra 59 sujeitos, sendo 21 no grupo controle (grupo A) e 38 no experimental (grupo B). Os critérios de inclusão foram: concordância em participar e possuir no mínimo um ano de atividade na Unidade atual de trabalho. Os de exclusão foram: enfermeiros afastados devido a férias ou licença médica no período da coleta de dados e os atuantes na pediatria. Os critérios de descontinuidade foram: enfermeiros Que se ausentaram por algum motivo de uma das três etapas da pesquisa.

Para a coleta dos dados utilizou-se um instrumento contendo duas partes: parte A - dados de identificação e caracterização dos enfermeiros; parte $\mathrm{B}$ - Questionário abordando o conteúdo sobre PCR/RCP, adaptado do instrumento elaborado por CAPOVILLA ${ }^{(7)}$, acrescido de Quatro Questões $\left(n^{\circ} 3,5,16\right.$ e 17), totalizando 17. As perguntas foram dispostas em seQüência lógica e compatível com as DIRETRIZES-2000 do atendimento da PCR. Nas etapas II e III foi acrescida, no instrumento, a Questão ${ }^{\circ} 18$, referente ao contato dos sujeitos, de ambos os grupos, com a PCR. Um roteiro explicativo do instrumento com descrição dos itens, Questões e conteúdos das respostas foi criado para utilização dos pesquisadores.

O programa de capacitação foi executado em três etapas denominadas: Etapa I: avaliação prévia e capacitação teórica dos enfermeiros; Etapa II: avaliação teórica recente; e Etapa III: avaliação teórica tardia. As etapas I e II foram realizadas em seeüência, com intervalos de uma semana, e a etapa III após três meses da etapa II.

A capacitação teórica contemplou três momentos, a saber: $1^{\circ}$ Momento: sensibilização (grupo B, 30 min); $2^{\circ}$ Momento: aplicação do instrumento (Grupos A e B, 30min); e $3^{\circ}$ Momento: aula expositiva (Grupo B, 2h). No primeiro momento foi abordado, para o grupo $\mathrm{B}$, alguns aspectos relacionados à $\mathrm{PCR} / \mathrm{RCP}$, a fim de introduzí-los no assunto. O segundo foi para responder às Questões (Grupos A e B). A abordagem do conteúdo teórico seguiu a seQüência do atendimento da PCR, para facilitar sua compreensão (grupo-B, experimental), apresentados com recurso multimídia, Que tiveram como títulos os tópicos referentes a cada Questão.

Decorrida uma semana, foi realizada a etapa II, e, após três meses, a etapa III, Que consistiram de uma reavaliação com a reaplicação do Questionário para ambos os grupos. Os instrumentos foram identificados segundo denominação previamente estabelecida. Essas atividades foram realizadas nas dependências do Hospital.

As respostas obtidas foram consideradas corretas Quando todos os conteúdos mínimos foram descritos e/ou assinalados; parcialmente corretas Quando um ou mais conteúdos mínimos não 
foram descritos e/ou assinalados; e incorretas Quando nenhum dos conteúdos mínimos foi descrito e/ou assinalado.

Foi dado a cada Questão o valor de um ponto, totalizando 16 pontos. As Questões de no 17 e 18 não foram consideradas para efeitos de pontuação. Nas Questões com mais de uma alternativa correta, dividiu-se o valor I pelo número de alternativas, excluindose as não sei e outras respostas, para se obter o valor de cada uma delas. As respostas das Questões dissertativas ( $n^{\circ} 7$ e 14) foram divididas em partes, e a cada uma atribuiu-se a fração do valor em relação ao valor total da Questão. Com a obtenção do número de pontos, realizou-se a regra de três para transformá-los em nota com valores de zero a dez.

Os dados das três aplicações do instrumento foram tabulados. Na comparação das variáveis categóricas entre os grupos utilizaramse os testes Qui-Quadrado e exato de Fisher. Para as variáveis contínuas aplicou-se o teste de Mann-Whitney. Para analisar a evolução dos escores entre as etapas e os grupos foi utilizada a análise de variância (ANOVA). O teste de Tukey foi utilizado na comparação entre os grupos em cada tempo, e o teste de perfil por contraste para a comparação das medidas entre os tempos. O nível de significância adotado foi de $5 \%(p<0,05)$.

O projeto foi aprovado pelo Comitê de Ética em Pesquisa da instituição sob parecer no4 15/2004 e os participantes assinaram o Termo de Consentimento Livre e Esclarecido.

\section{RESULTADOS}

Observou-se uma predominância do sexo feminino em ambos os grupos (17/21 no grupo A e 32/38 no $B ; p=N S)$. A faixa etária predominante esteve entre 30-39 anos (1 I/2 I no grupo A e 15/ 38 no $B ; p=N S)$. A média de idade, em anos, no grupo $A$ foi

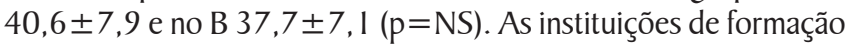
dos participantes foram as seguintes: Faculdade de Enfermagem de Araras (9/2 I); Unicamp (3/2 I), PUC-Campinas (2/2 I) e outras (7/21) no grupo A. No grupo B, foram: PUC-Campinas (1 1/38), Unicamp e Araras (8/38 cada) e outras instituições (1 1/38).

Quanto à pós-graduação (latu sensu), 1 I/2 I no grupo A e 16/ 38 no grupo $B$ referiram ter curso de especialização $(p=N S)$. Em relação à participação nos cursos de $S B V$ e $S A V$, verificou-se Que uma minoria do grupo A relatou ter participado: SBV (2/2 I) e SAV $(1 / 21)$, assim como no B, SBV (9/38) e SAV (5/38) ( $p=N S)$.

No grupo $A$, houve maior participação no programa de capacitação dos enfermeiros da Emergência Clínica (EC)/Cirurgia do Trauma (CT)/TMO/ Psieuiatria (9/2 I), do Serviço de MédicoCirúrgica (SEMC) II (5/2I); o SEMC I, Unidade de Emergência Referenciada (UER) e Unidade de Terapia Intensiva (UTI) (2/2I) cada, e o centro cirúrgico (1/21). O grupo B apresentou maior variação de participação sendo: SEMC I (13/38); SEMC II (I0/ 38); EC/CT/TMO/Psiquiatria (7/38); UER (5/38); UTI (2/38) e radioterapia $(1 / 38)$.

Em relação à abordagem sobre já ter atuado em outra Unidade na Instituição, 11/21 dos enfermeiros do grupo A e 18/38 do B, responderam afirmativamente.

A distribuição dos enfermeiros por turno de trabalho e se trabalhavam em outras instituições apontou, sobre o primeiro aspecto, um maior índice de participação do noturno nos grupos A (1 I/2 I) e B (17/38). Os do turno da tarde foram 7/21 no A e
12/38 no B. Os do turno manhã apresentaram menor índice de participação, 3/2 I no A e 9/38 no B ( $p=N S)$. Quanto ao segundo aspecto, no grupo A obteve-se 1 1/2 I e no B 18/38 de respostas $\operatorname{sim}(\mathrm{p}=\mathrm{NS})$.

Para a análise comparativa dos locais de maior e menor incidência de PCR foram agrupados os serviços de cardiologia/ pneumologia, EC/CT, UTI e UER como local I (maior), e, os demais, como local 2 (menor). Observou-se Que no grupo A 10/ 21 referiram trabalhar no local I e II/2 I no local 2. No B, I5/38 referiram local 1 e 23/38 local 2 ( $p=N S$ ).

Sobre atualização em PCR/RCP, 3/2 I enfermeiros no grupo A referiram ter se atualizado há $21 \pm 24$ meses. No grupo $B, 16 / 38$ referiram ter se atualizado há $39 \pm 34$ meses $(p=0,275$-MannWhitney). Com relação ao envolvimento em situações de PCR/ RCP, observou-se Que 13/2 I enfermeiros do grupo A e 14/38 do B referem raro contato, e, respectivamente, 8/2 I e 24/38 contato freqüente ( $p=0,041$-Qui-Quadrado). As formas de atualização dos sujeitos do grupo A foram: a leitura de livros (9/13), palestras $(6 / 13)$, aulas (6/13), cursos (4/13), leituras em periódicos (1/13) e outras formas (2/13). No grupo $B$, os livros e palestras foram 14/28 cada, aulas (1 I/28), periódicos (8/28), cursos (9/28) e 3/ 28 de outras formas.

As variáveis: tempo de formação, trabalho na unidade e na instituição, de realização dos cursos de SBV/SAV e da última atualização sobre PCR dos participantes dos grupos A e B foram semelhantes entre si ( $p>0,05-$ Mann-Whitney).

Com relação ao tempo de formado, um sujeito do grupo A não respondeu. Dos 20 restantes, a média (em meses) foi $144 \pm 67$ e no $B, 144 \pm 74$. A média do tempo de trabalho (em meses) na unidade foi de $88 \pm 51$ no grupo A e $88 \pm 63$ no B. O tempo de trabalho na instituição obteve média de $128 \pm 71$ meses no grupo A e $125 \pm 78$ no B ( $p=N S)$.

Quanto à participação em cursos, dois respondentes do grupo A realizaram o SBV há dois anos, e um participante fez referência à realização do $\mathrm{SAV}$. No $\mathrm{B}$, nove sujeitos realizaram o $\mathrm{SBV}$, com tempo médio de $93 \pm 71$ meses, e cinco realizaram o SAV, com média de tempo de $89 \pm 32$ meses.

O comportamento das respostas das 18 Questões do instrumento - conhecimento teórico, nas três etapas do estudo, de ambos os grupos, foram agrupados em três grandes blocos, descritos no Quadro 1.

Na Questão I, sobre detecção da PCR, nos enfermeiros do grupo A houve um aumento de respostas $C$ das etapas I e II (52\%) para a III (71\%). No grupo B, o percentual de C foi $45 \%$ na etapa I, com aumento expressivo destas nas etapas II e III, 82\% e 84\%, respectivamente (B > A na etapa II; $p=0,0$ I8-Qui - Quadrado).

Em relação às condutas imediatas a serem tomadas após o diagnóstico da PCR, Questão 2, os grupo A e B apresentaram aumento de respostas $C$ da etapa I à III, porém sem diferenças significativas entre eles $(p>0,05)$.

Sobre os padrões de ritmos na PCR, Questão 3, nas três etapas o grupo A obteve baixos percentuais de $\mathrm{C}$. No grupo $\mathrm{B}$, houve aumento de respostas $C$ da etapa I (32\%) para as II e III $(87 \%$ e $76 \%$, respectivamente; grupo B $>$ A nas etapas II e III; $p<0,00$ I e $p=0,002$ ).

Quanto ao SBV, Questão 4, verificou-se, no grupo A, baixas percentagens de respostas $C$ nas três etapas ( $5 \%$ a I $4 \%$ ). No grupo 


\begin{tabular}{|c|c|c|c|c|c|c|c|c|c|c|}
\hline \multirow{2}{*}{$\begin{array}{l}\text { 莺 } \\
\text { పే, }\end{array}$} & \multirow{2}{*}{ 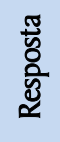 } & \multicolumn{3}{|c|}{ Grupo A } & \multicolumn{3}{|c|}{ Grupo B } & \multicolumn{3}{|c|}{$\mathrm{p}$ valor } \\
\hline & & $\begin{array}{c}\text { Etapa I } \\
\text { n (\%) }\end{array}$ & $\begin{array}{c}\text { Etapa II } \\
\text { N (\%) }\end{array}$ & $\begin{array}{c}\text { EtapalII } \\
\text { n (\%) }\end{array}$ & $\begin{array}{l}\text { Etapa I } \\
\text { N (\%) }\end{array}$ & $\begin{array}{c}\text { Etapa II } \\
\text { n (\%) }\end{array}$ & $\begin{array}{c}\text { EtapalII } \\
\text { n (\%) }\end{array}$ & Etapa I & Etapa II & Etapa III \\
\hline \multirow{2}{*}{ QI } & $\mathrm{C}$ & $11(52,4)$ & $11(52,4)$ & $15(71,4)$ & $17(44,7)$ & $3 I(81,6)$ & $32(84,2)$ & \multirow{2}{*}{0,573} & \multirow{2}{*}{$0,018 *$} & \multirow{2}{*}{0,315} \\
\hline & PC & $10(47,6)$ & $10(47,6)$ & $06(28,6)$ & $21(55,3)$ & $07(18,4)$ & $06(15,8)$ & & & \\
\hline \multirow{2}{*}{ Q2 } & $\mathrm{C}$ & $07(33,3)$ & $13(61,9)$ & $14(66,7)$ & $18(47,4)$ & $27(71,1)$ & $25(65,8)$ & \multirow{2}{*}{0,296} & \multirow{2}{*}{0,472} & \multirow{2}{*}{0,946} \\
\hline & PC & $14(66,7)$ & $08(38,1)$ & $07(33,3)$ & $20(52,6)$ & $11(28,9)$ & $13(34,2)$ & & & \\
\hline \multirow{4}{*}{ Q3 } & $\mathrm{C}$ & $02(9,5)$ & $05(23,8)$ & $07(33,3)$ & $12(31,6)$ & $33(86,8)$ & $29(76,3)$ & \multirow{4}{*}{0,157} & \multirow{4}{*}{$\underset{0,00 I^{* *}}{<}$} & \multirow{4}{*}{$0,002 * *$} \\
\hline & PC & $18(85,7)$ & $15(71,4)$ & $13(61,9)$ & $25(65,8)$ & $05(13,2)$ & $09(23,7)$ & & & \\
\hline & I & $01(4,8)$ & $01(4,8)$ & 00 & 00 & 00 & 00 & & & \\
\hline & NS & 00 & 00 & $01(4,8)$ & $01(2,6)$ & 00 & 00 & & & \\
\hline \multirow{4}{*}{ Q4 } & $\mathrm{C}$ & $01(4,8)$ & $03(14,3)$ & $03(14,3)$ & $07(18,9)$ & $20(52,6)$ & $19(50,0)$ & \multirow{4}{*}{0,363} & \multirow{4}{*}{$\begin{array}{c}< \\
0,001^{* *}\end{array}$} & \multirow{4}{*}{$0,007 *$} \\
\hline & PC & $18(85,7)$ & $17(81,0)$ & $18(85,7)$ & $29(78,4)$ & $18(47,4)$ & $19(50,0)$ & & & \\
\hline & IC & 00 & $01(4,8)$ & 00 & 00 & 00 & 00 & & & \\
\hline & NS & $02(9,5)$ & 00 & 00 & $01(2,7)$ & 00 & 00 & & & \\
\hline \multirow{4}{*}{ Q5 } & $C$ & $06(28,6)$ & $06(28,6)$ & $10(47,6)$ & $09(23,7)$ & $25(65,8)$ & $25(65,8)$ & \multirow{4}{*}{0,886} & \multirow{4}{*}{$0,006^{*}$} & \multirow{4}{*}{0,174} \\
\hline & PC & $14(66,7)$ & $15(71,4)$ & $1 \mathrm{I}(52,4)$ & $28(73,7)$ & $13(34,2)$ & $13(34,2)$ & & & \\
\hline & IC & $01(4,8)$ & 00 & 00 & $01(2,6)$ & 00 & 00 & & & \\
\hline & NR & 00 & 00 & 00 & 00 & 00 & 00 & & & \\
\hline
\end{tabular}

$C=$ correta; $P C=$ parcialmente correta; $I C=$ Incorreta; $N R=$ Não respondeu; $N S=$ Não sei; * - Teste Qui-Quadrado ; ** - Teste Exato de Fisher.

Quadro 1.- Comportamento das respostas das questões I a 5, sobre o conhecimento teórico, nas Etapas I, II e III de ambos os grupos. Campinas, 2005.

\begin{tabular}{|c|c|c|c|c|c|c|c|c|c|c|}
\hline \multirow{2}{*}{ 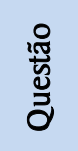 } & \multirow{2}{*}{ 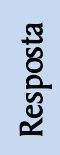 } & \multicolumn{3}{|c|}{ Grupo A } & \multicolumn{3}{|c|}{ Grupo B } & \multicolumn{3}{|c|}{$p$ valor } \\
\hline & & $\begin{array}{c}\text { Etapa I } \\
\text { n (\%) }\end{array}$ & $\begin{array}{c}\text { Etapa II } \\
\text { n (\%) }\end{array}$ & $\begin{array}{c}\text { Etapa III } \\
\text { n (\%) }\end{array}$ & $\begin{array}{c}\text { Etapa I } \\
\text { n (\%) }\end{array}$ & $\begin{array}{c}\text { Etapa II } \\
\text { n (\%) }\end{array}$ & $\begin{array}{c}\text { Etapa III } \\
\text { n (\%) }\end{array}$ & Etapa I & Etapa II & Etapa III \\
\hline \multirow{2}{*}{ Q6 } & $\mathrm{C}$ & 00 & 00 & $02(9,5)$ & $03(7,9)$ & $13(34,2)$ & $10(26,3)$ & \multirow{2}{*}{0,546} & \multirow{2}{*}{$0,002 * *$} & \multirow{2}{*}{0,182} \\
\hline & $\mathrm{PC}$ & $21(100)$ & $21(100)$ & $19(90,5)$ & $35(92,1)$ & $25(65,8)$ & $28(73,7)$ & & & \\
\hline \multirow{4}{*}{ Q7 } & $\mathrm{C}$ & 00 & 00 & 00 & 00 & $02(5,3)$ & $0 \mid(2,6)$ & \multirow{4}{*}{0,260} & \multirow{4}{*}{0,229} & \multirow{4}{*}{0,394} \\
\hline & PC & $18(85,7)$ & $16(76,2)$ & $16(76,2)$ & $25(65,8)$ & $33(86,8)$ & $33(86,8)$ & & & \\
\hline & IC & $03(14,3)$ & $05(23,8)$ & $04(19,0)$ & $11(28,9)$ & $03(7,9)$ & $03(7,9)$ & & & \\
\hline & NR & 00 & 00 & $01(4,8)$ & $02(5,3)$ & 00 & $01(2,6)$ & & & \\
\hline \multirow{3}{*}{ Q8 } & $\mathrm{C}$ & $10(47,7)$ & $14(66,7)$ & $12(57,1)$ & $19(50,0)$ & $31(81,6)$ & $27(71,1)$ & \multirow{3}{*}{0,999} & \multirow{3}{*}{0,218} & \multirow{3}{*}{0,280} \\
\hline & PC & $11(52,4)$ & $07(33,3)$ & $09(42,9)$ & $18(47,4)$ & $07(18,4)$ & II $(28,9)$ & & & \\
\hline & IC & 00 & 00 & 00 & $01(2,6)$ & 00 & 00 & & & \\
\hline \multirow{3}{*}{ Q9 } & $\mathrm{C}$ & $19(90,5)$ & $19(90,5)$ & $18(85,7)$ & $33(86,8)$ & $36(94,7)$ & $38(100)$ & \multirow{3}{*}{0,999} & \multirow{3}{*}{0,708} & \multirow{3}{*}{0,041 ** } \\
\hline & IC & $02(9,5)$ & $02(9,5)$ & $03(14,3)$ & $04(10,5)$ & $01(2,6)$ & 00 & & & \\
\hline & NR & 00 & 00 & 00 & $0 I(2,6)$ & $0 I(2,6)$ & 00 & & & \\
\hline \multirow{2}{*}{ Q10 } & $\mathrm{C}$ & $18(85,7)$ & $17(81,0)$ & $15(71,4)$ & $30(78,9)$ & $38(100)$ & $34(89,5)$ & \multirow{2}{*}{0,730} & \multirow{2}{*}{$0,013 * *$} & \multirow{2}{*}{0,144} \\
\hline & IC & $03(14,3)$ & $04(19,0)$ & $06(28,6)$ & $08(2 \mathrm{I}, \mathrm{I})$ & 00 & $04(10,5)$ & & & \\
\hline \multirow{2}{*}{ Q11 } & $\mathrm{C}$ & $14(66,7)$ & $\mathrm{I} 4(66,7)$ & $15(71,4)$ & $20(52,6)$ & $37(97,4)$ & $34(89,5)$ & \multirow{2}{*}{0,296} & \multirow{2}{*}{$0,002 * *$} & \multirow{2}{*}{0,144} \\
\hline & IC & $07(33,3)$ & $07(33,3)$ & $06(28,6)$ & $18(47,4)$ & $01(2,6)$ & $04(10,5)$ & & & \\
\hline
\end{tabular}

$C=$ correta; $P C=$ parcialmente correta; $I C=$ Incorreta; $N R=$ Não respondeu; $N S=$ Não sei. * Teste Qui-Quadrado; ** Fisher

Quadro 2. Comportamento das respostas das Questões 6 a 11, sobre o conhecimento teórico, nas Etapas I, II e III de ambos os grupos. Campinas, 2005.

B, apesar de poucas respostas C na etapa I (19\%), na etapa II houve um maior equilíbrio entre as C e PC (53\% vs 47\%), assim como na III ( $50 \%$ para ambas) (respostas $\mathrm{C}$ do grupo $\mathrm{B}>\mathrm{A}$, nas etapas II e III; $p<0,001$ e $p=0,007$, respectivamente).

Na Questão 5, sobre o SAV, o grupo A, na etapa I, obteve $29 \%$ de C, Que se manteve na II, aumentando para $48 \%$ na III. No grupo B, etapa I, houve $24 \%$ de C, com aumento destas para $66 \%$ nas etapas II e III (respostas C no grupo B > A na etapa II; $\mathrm{p}=0,006)$, conforme apresentados no Quadro 2 .

Sobre as possíveis maneiras de se ventilar o paciente durante a RCP, Questão 6, mostrou, no grupo A, uma baixa porcentagem de respostas $C(<10 \%)$ e que foram semelhantes nas três etapas. No grupo B, na etapa II houve aumento discreto das respostas $\mathrm{C}$ em relação à etapa I ( $34 \%$ vs $8 \%$ ), diminuindo novamente na etapa III (26\%) (respostas corretas grupo B > A na etapa II; $p=0,002$ ).

Como e onde posicionar as mãos para realizar a compressão 
torácia externa (CTE), Questão 7, apesar de elevada manifestação de sim em relação ao saber, não foram dadas respostas $C$ pelos sujeitos do grupo A e poucas do B, nas três etapas. As respostas PC foram predominantes (66 a 87\%) nos dois grupos nas três etapas $(p=N S)$.

Na Questão 8, como deve ser a postura corporal para a realização da CTE, as respostas $C$ nas três etapas, no grupo A, foram: $48 \%$, $67 \%$ e $57 \%$, respectivamente, e, no B, estas foram de $50 \%, 82 \%$ e $71 \%(\mathrm{p}=\mathrm{NS})$.

Quanto à abordagem sobre a posição utilizada para colocação dos eletrodos (pás) na desfibrilação (Questão 9), ambos os grupos apresentaram elevado número de respostas $\mathrm{C}$, sendo, no grupo $\mathrm{A}$, de $90 \%$ nas etapas I e II e $86 \%$ na III. O desempenho do B foi de $87 \%, 95 \%$ e I $100 \%$, respectivamente (B > A na etapa III; $p=0,04 \mathrm{I}$ ).

Os resultados obtidos na Questão 10 , relacionado à carga inicial para desfibrilação, foram, nas três etapas, no grupo A, 86\%, 81\% e $71 \%$ de corretas, respectivamente, e, no B, 79\%, 100\% e $89 \%$ (B > A na etapa II; $p=0,013$ ).

Sobre a carga máxima para desfibrilação (Questão 11 ), no grupo A, apontou $67 \%$ de respostas C nas etapas I e II, e $71 \%$ na III. No grupo $\mathrm{B}$, obteve-se $53 \%$ de $\mathrm{C}$ na etapa I, com aumento importante na II (97\%) e discreta diminuição na III (89\%) (B > A na etapa II; $\mathrm{p}=0,002$ ) (Quadro 3).

As respostas corretas sobre as vias Que podem ser utilizadas para administração de fármacos na RCP, Questão 12 , apresentaram diferença significativa entre os grupos na etapa II (B > A; $\mathrm{p}<0,001$ ).

A Questão 13, relacionada aos fármacos utilizados na PCR, mostrou baixo índice de corretas $(<10 \%)$ no grupo A nas três etapas. No $B$, etapa I, não houve resposta $C$, e, nas outras etapas, não atingiram $50 \%$ (B > A, etapas II e III; $p=0,002$ e $p=0,024$, respectivamente).

Na primeira parte da Questão 14 (sim e não), sobre o conhecimento da finalidade dos fármacos da Questão anterior, dos sujeitos do grupo A, 43\% responderam conhecer na etapa I, 62\% na II e $43 \%$ na III. No B, 53\% na I, 45\% na II e 58\% na III. Entretanto, na descritiva verificou-se Que praticamente não houve respostas corretas nas três etapas em ambos os grupos.

O conteúdo dos registros de enfermagem na PCR, Questão 15 , no grupo A, obteve-se respostas C de 19\%, 24\% e 48\%, nas etapas I, II e III, respectivamente. No grupo B, as respostas $C$ foram $58 \%$, $76 \%$ e $71 \%$ (B > A, etapas I e II; $p=0,008$ e $p<0,00$ I, respectivamente)

Em relação ao conteúdo do carrinho de emergência (Questão 16), observou-se no $A$ que as respostas $C$ foram $38 \%$ na etapa I e atingiram 62\% na III; já, no B, na I, estas iniciaram com 34\%, atingiram $84 \%$ na II, caindo para $74 \%$ na III (B > A na etapa II; $\mathrm{p}=0,007)$.

A Questão 17, sobre o responsável pela checagem do carrinho, evidenciou no grupo A Que $62 \%$ dos participantes na etapa I

\begin{tabular}{|c|c|c|c|c|c|c|c|c|c|c|}
\hline \multirow{2}{*}{ 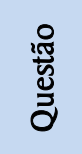 } & \multirow{2}{*}{ 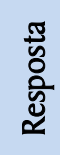 } & \multicolumn{3}{|c|}{ Grupo A } & \multicolumn{3}{|c|}{ Grupo B } & \multicolumn{3}{|c|}{$\mathrm{p}$ valor } \\
\hline & & $\begin{array}{c}\text { Etapa I } \\
\text { n (\%) }\end{array}$ & $\begin{array}{c}\text { Etapa II } \\
\text { n (\%) }\end{array}$ & $\begin{array}{c}\text { EtapallI } \\
\mathrm{n}(\%)\end{array}$ & $\begin{array}{c}\text { Etapa I } \\
\text { n (\%) }\end{array}$ & $\begin{array}{c}\text { Etapa II } \\
\text { n (\%) }\end{array}$ & $\begin{array}{c}\text { EtapallI } \\
\mathrm{n}(\%)\end{array}$ & Etapa I & Etapa II & Etapa III \\
\hline \multirow{2}{*}{ Q12 } & $\mathrm{C}$ & $05(23,8)$ & $05(23,8)$ & $10(47,6)$ & $10(26,3)$ & $30(78,9)$ & $25(65,8)$ & \multirow{2}{*}{0,832} & & \multirow{2}{*}{0,174} \\
\hline & PC & $16(76,2)$ & $16(76,2)$ & $1 \mathrm{I}(52,4)$ & $28(73,7)$ & $08(21,1)$ & $13(34,2)$ & & $0,001 *$ & \\
\hline \multirow{3}{*}{ Q13 } & $\mathrm{C}$ & $0 I(4,8)$ & $0 I(4,8)$ & $02(9,5)$ & 00 & $16(42,1)$ & $14(36,8)$ & \multirow{3}{*}{0,589} & \multirow{3}{*}{$0,002 *$} & \multirow{3}{*}{$0,024 *$} \\
\hline & PC & $20(95,2)$ & $20(95,2)$ & $19(90,5)$ & $37(97,4)$ & $22(57,9)$ & $24(63,2)$ & & & \\
\hline & NR & 00 & 00 & 00 & $01(2,6)$ & 00 & 00 & & & \\
\hline \multirow{4}{*}{ Q14 } & $\mathrm{C}$ & 00 & 00 & 00 & $01(2,6)$ & $01(2,6)$ & $01(2,6)$ & \multirow{4}{*}{0,185} & \multirow{4}{*}{$0,023 * *$} & \multirow{4}{*}{0,255} \\
\hline & PC & $15(71,4)$ & $12(57,1)$ & $14(66,7)$ & $20(52,6)$ & $3 I(81,6)$ & $28(73,7)$ & & & \\
\hline & IC & $06(28,6)$ & $08(38,1)$ & $0733,3)$ & $11(28,9)$ & $03(7,9)$ & $06(15,8)$ & & & \\
\hline & NR & 00 & $0 \perp(4,8)$ & 00 & $06(15,8)$ & $03(7,9)$ & $03(7,9)$ & & & \\
\hline \multirow{4}{*}{ Q15 } & $\mathrm{C}$ & $04(19,0)$ & $05(23,8)$ & $10(47,6)$ & $22(57,9)$ & $29(76,3)$ & $27(71,1)$ & \multirow{4}{*}{$0,008 * *$} & \multirow{4}{*}{$\begin{array}{c}< \\
0,00 I^{* *}\end{array}$} & \multirow{4}{*}{0,075} \\
\hline & PC & $16(76,2)$ & $15(71,4)$ & $1 \mathrm{I}(52,4)$ & $15(39,5)$ & $09(23,7)$ & $11(28,9)$ & & & \\
\hline & IC & $01(4,8)$ & 00 & 00 & $0 \mid(2,6)$ & 00 & 00 & & & \\
\hline & NR & 00 & $0 I(4,8)$ & 00 & 00 & 00 & 00 & & & \\
\hline \multirow{3}{*}{ Q16 } & $\mathrm{C}$ & $08(38,1)$ & $10(47,6)$ & $13(61,9)$ & $13(34,2)$ & $32(84,2)$ & $28(73,7)$ & \multirow{3}{*}{0,765} & \multirow{3}{*}{$0,007 * *$} & \multirow{3}{*}{0,347} \\
\hline & PC & $13(61,9)$ & $10(47,6)$ & $08(38,1)$ & $25(65,8)$ & $06(15,8)$ & $10(26,3)$ & & & \\
\hline & IC & 00 & $0 \perp(4,8)$ & 00 & 00 & 00 & 00 & & & \\
\hline \multirow{3}{*}{ Q17 } & C & $13(61,9)$ & $11(52,4)$ & $09(42,9)$ & $16(42,1)$ & $25(65,8)$ & $22(57,9)$ & 0,145 & 0,305 & 0,268 \\
\hline & IC & $08(38,1)$ & $09(42,9)$ & $12(57,1)$ & $22(57,9)$ & $13(34,2)$ & $16(42,1)$ & \multirow{2}{*}{-} & \multirow[b]{2}{*}{-} & \multirow[b]{2}{*}{-} \\
\hline & NR & 00 & $01(4,8)$ & 00 & 00 & 00 & 00 & & & \\
\hline \multirow{3}{*}{ Q18 } & $S$ & - & $03(14,3)$ & $10(47,6)$ & - & - & $24(63,2)$ & \multirow{3}{*}{ - } & \multirow{3}{*}{ - } & \multirow{3}{*}{ - } \\
\hline & $\mathrm{N}$ & - & $17(81,0)$ & $10(47,6)$ & - & - & $14(36,8)$ & & & \\
\hline & NR & - & $01(4,8)$ & $0 I(4,8)$ & - & - & 00 & & & \\
\hline
\end{tabular}

$C=$ correta; $P C=$ parcialmente correta; $I C=$ Incorreta; $N R=$ não respondeu; $N S=$ não sei; * - Teste Qui-Quadrado ; ** - Teste Exato de Fisher

Quadro 3. Comportamento das respostas das Questões 12 a 18, sobre o conhecimento teórico, nas Etapas I, II e III de ambos os grupos. Campinas, 2005. 


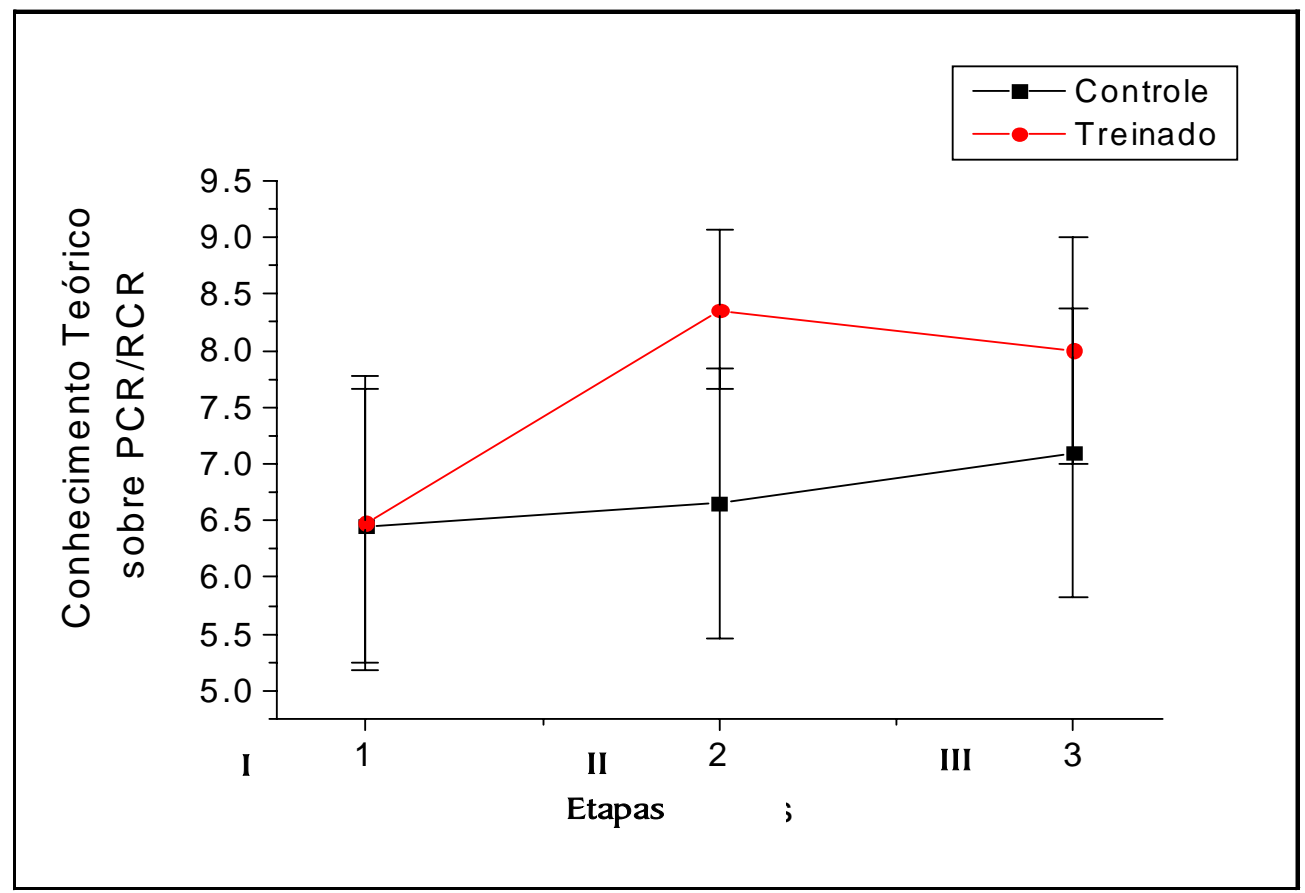

Figura 1. Efeito interação das notas do conhecimento teórico sobre PCR/RCP entre os grupos nas três etapas. Campinas, 2005.

Tabela 1. Comportamento das médias das notas, nas três etapas de ambos os grupos. Campinas, 2005.

\begin{tabular}{|c|c|c|c|c|c|c|c|c|c|c|c|}
\hline \multirow{2}{*}{ Etapas } & \multirow[b]{2}{*}{$\mathrm{n}$} & \multicolumn{4}{|c|}{ Grupo A } & \multicolumn{5}{|c|}{ Grupo B } & \multirow{2}{*}{$p$ valor } \\
\hline & & Média (DP) & Mediana & Mínima & Máxima & $n$ & Média (DP) & Mediana & Mínima & Máxima & \\
\hline I & & $6,45(1,21)$ & 6,65 & 2,44 & 7,69 & & $6,48(1,30)$ & 6,65 & 3,50 & 8,56 & \\
\hline II & 21 & $6,66(1,19)$ & 6,70 & 2,38 & 8,00 & 38 & $8,36(0,70)$ & 8,55 & 6,82 & 9,51 & $<0,001$ * \\
\hline III & & $7,10(1,28)$ & 7,38 & 3,16 & 7,38 & & $8,00(1,00)$ & 8,14 & 5,18 & 9,89 & \\
\hline
\end{tabular}

consideraram como sendo o enfermeiro, caindo para $43 \%$ na etapa III. No grupo B, iniciaram com $42 \%$ atingiram $66 \%$ na II e $58 \%$ na III $(\mathrm{p}=\mathrm{NS})$.

Na Questão 18, perguntava-se da busca de informação sobre PCR aos sujeitos do A, e do contato com a PCR aos do B após participar do programa de capacitação, na etapa III. Apenas 14\% dos sujeitos do A responderam sim para a busca na etapa II, e $48 \%$ na III. No grupo B, 63\% mencionaram contato, e, destes, 55\% consideraram seu atendimento satisfatório, $8 \%$ pouco e $37 \%$ não satisfatório.

A Fgura I mostra o efeito interação das notas do conhecimento teórico sobre PCR/RCP entre os grupos nas três etapas. Observase Que os sujeitos do grupo $B$, apresentaram aumento significativo na etapa II, leve Queda na III, decorridos três meses; ao passo Que os do grupo A apresentaram nas etapas II e III discreto aumento.

Os dados da Tabela I demonstram o comportamento das médias das notas, nas três etapas de ambos os grupos. Os sujeitos do grupo B obtiveram melhora no desempenho em relação ao grupo A $(\mathrm{p}<0,00$ I-Tukey).

Houve diferenças, no grupo A, entre as etapas I e III $(p<0,004)$ e etapas II e III $(p=0,010)$. No grupo $B$, houve diferenças entre as etapas I e II $(p<0,001)$; I e III $(p<0,001)$ e II e III $(p=0,005$; Teste de Perfil).

\section{DISCUSSÃO}

O critério de avaliação adotado para a correção das alternativas do instrumento de coleta dos dados teve como base as Diretrizes2000, uma vez Que era a vigente no período da elaboração e aplicação do instrumento. No entanto, a discussão apontará também as alterações presentes nas Diretrizes-2005.

Este estudo reforçou a importância e benefícios conquistados com a realização do curso para a capacitação de enfermeiros, como mostraram os dados.

Observou-se também Que em relação à detecção da PCR ambos os grupos, A e B apresentaram percentuais próximos de $50 \%$ na etapa I, com aumento nas etapas II e III de respostas corretas, demonstrando conhecerem os dados da literatura vigente Que recomendava avaliação da inconsciência, ausência de respiração e de pulsos nas grandes artérias ${ }^{(13-14)}$. Porém, observou-se Que a ausência de consciência foi a alternativa menos assinalada pelos sujeitos de ambos os grupos. Apesar da inconsciência ser um dos 
sinais da $\mathrm{PCR}^{(14)}$, ela pode ser decorrente de outras alterações Que não esta e, por este fato, dificultar a confirmação do diagnóstico de PCR. De acordo com as Diretrizes-2005, a inconsciência (nãoresponsividade) associada à ausência de movimentos e de respiração ou "gasping" determinam o diagnóstico de PCR e estabelecem o início das manobras de ressuscitação ${ }^{(15)}$.

Considerando Que a realização da RCP pelo enfermeiro é um fator determinante nos índices de sobrevida da PCR, pois, normalmente, é o primeiro profissional presente nesse evento ${ }^{(4)}$, e, tendo o conhecimento e implementando as manobras de SBV, favorecerá o sucesso do atendimento ${ }^{(16)}$. Neste estudo, observouse Que a partir da etapa II, mais de $50 \%$ dos participantes de ambos os grupos apresentaram respostas corretas Quanto às condutas. A provável explicação para este resultado pode-se dever à busca espontânea pelo conhecimento nos sujeitos do grupo $A$ e à participação no programa de capacitação no B.

Reconhecer o ritmo cardíaco por meio da monitorização eletrocardiográfica ou com o uso das pás do desfibrilador agiliza o atendimento para a desfibrilação nos casos de PCR por FV/TVSP(17). Estudo Que comparou os acertos dos ritmos da PCR entre os enfermeiros de unidades com e sem equipamentos de monitorização cardíaca demonstrou Que este percentual foi maior no primeiro grupo $^{(18)}$. Nesta pesQuisa, os enfermeiros submetidos ao programa de capacitação apresentaram mais respostas corretas sobre os ritmos encontrados na PCR.

Pode-se observar Que nas Questões das definições sobre SBV e SAV, o grupo $B$ apresentou destaQue em relação às respostas corretas Quando comparado ao A. Este fato pode ser relacionado ao conteúdo abordado no programa, Que seguiu as padronizações do SBV/SAV, presentes nas Diretrizes-2000.

Quanto às possíveis formas de ventilação durante a RCP, o estudo mostrou baixo índice de respostas corretas, o Que denota desconhecimento ou resistência dos participantes em assinalar as alternativas relacionadas à ventilação mecânica ou à boca-a-boca como sendo outras possibilidades para ventilar o paciente. Este achado pode ser explicado pela utilização frequente de ressuscitador manual no ambiente hospitalar durante a RCP e pouca experiência na manipulação de ventiladores mecânicos. Na prática clínica, a ventilação mecânica não é muito utilizada na RCP. De acordo com a literatura(15) ${ }^{(15}$ um estudo Que avaliou a forma de ventilação (manual vs automática) de pacientes em PCR extra-hospitalar demonstrou Que as concentrações dos gases sangüíneos destes não apresentaram diferenças significativas.

Em relação à CTE, os sujeitos de ambos os grupos apresentaram respostas semelhantes no item posicionamento das mãos, ou seja, a maioria mostrou respostas PC. Já no subitem postura corporal, ambos mostraram percentuais próximos de $50 \%$ ou mais de corretas em todas as etapas.

O preconizado para a realização da CTE nas Diretrizes-2000 era uma freqüência de 100 compressões/min, na proporção de 15:2, sincronizadas ou não com as ventilações, com um ou dois socorristas $^{(13)}$. Na Diretriz vigente (2005), o recomendado é de 30:2, independente do número de socorristas. A ênfase é para a Qualidade (deprimir o tórax 4 a $5 \mathrm{~cm}$ ) e freqüência das compressões torácicas (100/min), assim como minimizar as interrupções das CTE. Havendo dois socorristas, recomenda-se o revezamento entre eles a cada dois minutos ${ }^{(15)}$.
Nas Questões 9, 10 e 11, relacionadas ao procedimento de desfibrilação, as respostas corretas, em ambos os grupos, permaneceu superior a $50 \%$ nas três etapas. Entretanto, houve diferenças significativas e distintas. Quanto à posição utilizada para colocação das pás-eletrodos na desfibrilação (Questão 9), houve diferença no desempenho dos sujeitos do B em relação ao A na etapa III. Nas Questões 10 el I, relacionadas às cargas inicial e máxima, respectivamente, houve diferença significativa entre os grupos na etapa II.

A desfibrilação precoce é hoje, sabidamente, um procedimento Que melhora consideravelmente o índice de sobrevida de um paciente em FV/TVSP(19-20). Nos Estados Unidos é facultado ao enfermeiro a realização deste procedimento, porém, no Brasil, tal responsabilidade cabe ao médico. $\mathrm{O}$ enfermeiro pode e deve saber reconhecer o ritmo, e isto agiliza o atendimento. Nas Diretrizes2000 , era recomendada a aplicação de até três choques consecutivos com cargas crescentes, sem interposição de CTE, no tratamento da FV/TVSP, enquanto Que nas Diretrizes-2005 a recomendação é de um único choque (360) monofásico ou 200J bifásico), seguido imediatamente de retomada da RCP, iniciando com as CTE, até completar cinco ciclos ou dois minutos, antes da verificação do pulso. Alguns autores ${ }^{(21-22)}$ sugerem e encorajam o uso de desfibriladores elétricos automáticos (DEA) em locais de baixa ocorrência de PCR e para indivíduos com dificuldade de reconhecer os ritmos. Identificando a PCR e dispondo de um DEA, a desfibrilação deve ser efetuada o mais rápido possívell(23).

A Questão 12, relacionada às vias de administração dos fármacos, na etapa II, apresentou diferença estatisticamente significativa das respostas, resultado Que reforça a necessidade de atualização dos profissionais após as mudanças Que ocorrem nas Diretrizes sobre RCP. Além disso, conhecer o efeito dos fármacos, modos de administração e mecanismos de absorção podem contribuir efetivamente para o sucesso da RCP. Em 2000, a via intra-óssea era pouco recomendada em virtude de pequenas evidências da sua eficácia ${ }^{(24)}$. A partir de 2005, as Diretrizes recomendam o uso das vias intravenosa e intra-óssea. Embora muitos medicamentos possam ser absorvidos pelo pulmão, a via endotraQueal não é recomendada como preferencial, pois as doses da maioria dos medicamentos por esta via são desconhecidas. Caso não haja disponibilidade de um acesso intravenoso ou intra-ósseo, a dose recomendada pela via endotraqueal é de 2,5 vezes a dose intravenosa ${ }^{(23,25)}$.

As medicações preconizadas nas Diretrizes-2000 eram: adrenalina, atropina, vasopressina, bicarbonato de sódio, lidocaína e amiodarona. Em 2005, permanecem as mesmas, exceto o bicarbonato de sódio, estando seu uso restrito à PCR por acidose metabólica ou hiperpotassemia, já Que alguns de seus efeitos adversos, como a redução da resistência vascular sistêmica, alcalose e hipernatremia, são freqüentes ${ }^{(25)}$. Nesta pesquisa, obteve-se elevado número de repostas PC em ambos os grupos, nas três etapas, mostrando o desconhecimento da finalidade destes fármacos. Estes dados sugerem Que o enfermeiro sente-se responsável apenas pela administração dos medicamentos, e não pelo conhecimento de suas ações farmacológicas.

Os benefícios dos registros do atendimento da PCR incluem: respaldo legal, comunicação entre os membros da equipe e detalhamento do Quadro do paciente. Além disso, devem ser feitos de acordo com o estabelecido pelo COREN, ou seja, de forma 
clara, concisa e objetiva, para Que as informações possam ser transmitidas e utilizadas por toda a eQuipe ${ }^{(26)}$. Um estudo ${ }^{(27)}$ verificou a viabilidade de um impresso para registro do atendimento e comunicação entre as equipes. Porém, na presente pesquisa evidenciou-se o desconhecimento de impressos para o registro da RCP e dos itens que devem constar na descrição do atendimento.

No hospital em Questão, é responsabilidade do enfermeiro a checagem do carrinho de parada. Apesar disso, houve percentuais elevados de respostas de Que o técnico também deve realizar, para conhecimento/familiarização do conteúdo.

Conhecer o conteúdo do carrinho de emergência e a disposição dos materiais pode significar o sucesso do atendimento. Uma pesQuisa ${ }^{(28)}$ aponta a manutenção dos recursos para o atendimento da PCR, tanto sob o aspecto da checagem dos materiais e equipamentos como pelo seu suprimento, de grande responsabilidade.

Em relação à Questão 18 , no grupo $\mathrm{A}$, etapa II, responderam afirmativamente pela busca espontânea de informação sobre PCR apenas 3/2 I e, na III, as respostas sim e não obtiveram os mesmos números (10/2 I). No grupo B, 24/38 mencionaram contato com a PCR após a capacitação, 21/38 consideraram seu atendimento satisfatório, 3/ 38 pouco satisfatório e 14/38 não satisfatório. Diante destes resultados, percebeu-se, nos indivíduos do grupo A, ao serem Questionados, uma preocupação na busca espontânea pelo conhecimento, e, nos do grupo B, o favorecimento da auto-avaliação e da atualização.

\section{CONCLUSÃO}

Os conteúdos abordados e os instrumentos utilizados para a avaliação subsidiaram de forma favorável a execução e avaliação do programa de capacitação elaborado e implementado para o atendimento de PCR/RCP pelos enfermeiros. Verificou-se Que o desempenho dos sujeitos do grupo B após uma semana (etapa II) foi superior em relação ao de três meses (etapa III).

O comportamento do desempenho dos enfermeiros do grupo A em relação aos do B diferiu na forma de apresentação, ou seja, observou-se melhora progressiva nas etapas do A, eneuanto, no grupo B, foi de forma oscilante. Mas, a partir da etapa II, os do B apresentaram conhecimentos superiores aos do grupo A sobre PCR/ RCP.

\section{CONSIDERAÇÕES FINAIS}

Diante destes resultados acredita-se Que o programa de capacitação elaborado poderá ser utilizado na instituição Que foi objeto deste estudo, com a possibilidade de ser adaptado para a utilização em outras instituições, e, também, atualizado a cada publicação das novas diretrizes. Sugere-se Que o programa de capacitação deva ser aplicado regularmente, com uma periodicidade trimestral ou semestral, pois, como pôde ser observado, há um nítido declínio do conhecimento com o passar do tempo.

\section{REFERÊNCIAS}

I. Horsted T, Rasmussen LS, Meyhoff CS, Nielsen SL. Long-term prognosis after out-of-hospital cardiac arrest. Resuscitation 2007: 72: 214-8.

2. Makinen M, Aune S, Niemi-Murola L, Herlitz I,Varpula T, Nurmi I et al. Assessment of CPR-D skills of nurses in Goteborg,Sweden and Espoo, Finland: teaching leadership makes a difference. Resuscitation 2007; 72(2): 264-9.

3. Barbero MG, Such JA. What are doing in cardiopulmonary resuscitation training Europe? An analysis of a survey. Resuscitation 1999; 4I(I): 225-236

4. Chellel A. The role of nurse in resuscitation attempts in hospitals. In: Chellel A. Resuscitation: a guide for nurses. London: Churchill Livingstone; 2000. p.33-48.

5. Murphy M, Fitzsimons D. Does attendance at an immediate life support course influence nurses' skill deployment during cardiac arrest? Resuscitation 2004; 62(I): 49-54.

6. Smith KK, Gilcreast D, Pierce, K .Evaluation of staff's retention of ACLS and BLS skills. Resuscitation 2008; 78(I): 59-65.

7. Capovilla NC. Ressuscitação cardiorrespiratória: uma análise do processo ensino/aprendizagem nas universidades públicas estaduais paulistas [dissertação]. Campinas: Faculdade Ciências Médicas, Universidade Estadual de Campinas; 2002.

8. Landers MG. Theory-practice gap in nursing: the role of the nurse teacher. I Adv Nurs 2000; 32(6): 1550-66.

9. Baskett P. Progress of the advanced life support courses in Europe and Beyond. Resuscitation 2004; 62(3): 31 1-3.

10. Baskett PIF, Nolan IP, Handley A, Soar J, Biarent D, Richmond S. European Resuscitation Council Guidelines for Resuscitation 2005 - Section 9. Principles of training in resuscitation.

\section{Resuscitation 2005; 67(SI): S181-SI 89}

11. Silva AR. Parada cardiorrespiratória em unidades de internação. Vivências do enfermeiro [dissertação]. Ribeirão Preto: Escola de Enfermagem de Ribeirão Preto, Universidade de São Paulo; 2006.

12. Backes VMS, Lino MM, Prado ML, Reibnitz KS, Canaver BP Competência dos enfermeiros na atuação como educador em saúde. Rev Bras Enferm 2008; 61 (6): 858-65.

13. Guidelines 2000 For Cardiopulmonary Resuscitation and Emergency Cardiovalscular Care. International Consensus on Science. Part 3. Adult basic life support. Resuscitation 2000; 46: 29-71.

14. Araujo S, Araujo IEM. Ressuscitação cardiorrespiratória. Medicina 200I; 34: 36-63.

15. International Liaison Committee on Resuscitation - Part 2: adult basic life support. Resuscitation 2005; 67: 187-201

16. Madden C. Undergraduate nursing students' aceuisition and retention of CPR knowledge and skills. Nurse Educ Today 2006; (26): 2 I 8-27.

17. Murphy M, Fitzsimons D. Does attendance at an immediate life support course influence nurses skill deployment during cardiac arrest? Resuscitation 2004;62(1): 49-54.

18. Bertoglio VM, Azzolin K, Souza EN, Rabelo ER. Tempo decorrido do treinamento em parada cardiorrespiratória e o impacto no conhecimento teórico de enfermeiros. Rev Gaúcha Enferm 2008; 29(3): 454-60.

19. Timerman S, Cruz FF, Cardoso LF Timerman A, RAMIRES IAF Desfibrilação imediata. Rev Soc Cardiol Estado de São Paulo 200I; (I I): 226-55. 
20. Deakin CD, Nolan IP. European Resuscitation Council Guidelines for Resuscitation 2005-Section 3. Electrical therapies: automated external defibrillators, defibrillation, cardioversion and pacing. Resuscitation 2005; 67(SI): 525-37.

21. Mattei LC, Mckay U, Lepper MW, Soar I. Do nurses and physiotherapists require training to use an automated external defibrillator? Resuscitation 2002; 53(3): 277-80.

22. Vanheusden ML, Santoro DC, Szpilman D, Batista CO, Correia LFB, Cruz Filho FS. Conceito fase-dependente na ressuscitação cardiopulmonar. Revista da SOCERJ 2007; 20(1): 60-4.

23. Aspectos mais relevantes das diretrizes da AHA sobre Ressuscitação Cardiopulmonar e Atendimento Cardiovascular de Emergência. Currents In Emergency Cardiovascular Care. 2006; 16(4): 1-28.

24. Guidelines 2000 For Cardiopulmonary Resuscitation and
Emergency Cardiovalscular Care. International Consensus on Science. Part 6. Advanced cardiovascular life support. Resuscitation 2000; 46: 109-62.

25. International Liaison Committee on Resuscitation - Part 4: advanced life support. Resuscitation 2005; 67:2 13 -47.

26. Conselho Regional da Enfermagem (SP). Decreto Lei 94.406 de 8 de junho de 1987. Documentos Básicos de Enfermagem. São Paulo: COREN; 2000.

27. Boaventura AP, Araújo IEM. Registro do atendimento da parada cardiorrespiratória no ambiente intra-hospitalar: aplicabilidade de um instrumento. Rev Gaúcha Enferm 2006; 27 (3): 434-42.

28. Silva SC, Padilha KG. Parada cardiorrespiratória na unidade de terapia intensiva: considerações teóricas sobre os fatores relacionados às ocorrências iatrogênicas. Rev Esc Enferm USP 2001; 35(4): 360-5. 